\title{
Simultaneous Estimation of Lafutidine and Domperidone by Ultraviolet Spectroscopy
}

\author{
Kiran Jadhav, ${ }^{1}$ D. L. Dhamecha, ${ }^{1}$ S. V. Ghadlinge, ${ }^{2}$ G. P. Asnani, ${ }^{1}$ and M. B. Patil ${ }^{1}$ \\ ${ }^{1}$ Department of Pharmaceutical Analysis, Genba Sopanrao Moze College of Pharmacy, Wagholi, Maharashtra, Pune 412207, India \\ ${ }^{2}$ Department of Formulation and Development, Alkem Laboratories Ltd., Panvel 410208, India
}

Correspondence should be addressed to Kiran Jadhav, kiranjadhav112@yahoo.co.in

Received 23 March 2012; Accepted 23 April 2012

Academic Editors: D. J. Fletouris and D. Patra

Copyright (c) 2012 Kiran Jadhav et al. This is an open access article distributed under the Creative Commons Attribution License, which permits unrestricted use, distribution, and reproduction in any medium, provided the original work is properly cited.

A simple, accurate, and precise method for simultaneous estimation of Lafutidine and Domperidone in combined-dosage form have been described. The method employs formation and solving of simultaneous equations using 279 and $284 \mathrm{~nm}$ as two analytical wavelengths. This method allows the simultaneous determination of Lafutidine and Domperidone in concentration ranges employed for this purpose with the standard deviation of $<1.0 \%$ in the assay of tablet.

\section{Introduction}

Lafutidine (LAF) is (furan-2-ylmethylsulphinyl)-N-[(Z)4-[4-(piperidinyl-methyl)-pyridin-2-yl) oxybut 2-enyl] acetamide (Figure 1) [1]. It is freely soluble in methanol, whereas it is practically insoluble in water. It is a second generation histamine $\mathrm{H}_{2}$-receptor antagonist used as an antiulcerative agent [2]. Domperidone (DOP) is chemically 5-chloro-1-[1-[3-(2-oxo-2,3-dihydro-1H-benzimidazol-1-

yl) propyl]-piperidin-4-yl]-1,3-dihydro- $2 H$-benzimidazol2-one (Figure 2) used as an antiemetic drug [3, 4]. A combination of these drugs, DOP $(10 \mathrm{mg})$ and LAF $(10 \mathrm{mg})$ is available as tablets for clinical practice. This unique combination has comprehensive acid control and prokinetic action which ensures better control and relief from reflux, gastric ulcers, and associated gastrointestinal (GIT) disorders. Many methods like HPLC ${ }^{4,5}, \mathrm{HPTLC}^{7}$, and LCMS $^{9}$ [5-9] have been described in the literature for the determination of DOP and LAF individually or in combination with others. However, there is no spectroscopic method reported for the simultaneous determination of these drugs either as active pharmaceutical ingredient or from dosage forms. The present work describes a simple, precise, and accurate simultaneous ultraviolet spectrophotometric method for simultaneous estimation of LAF and DOP in combined dosage forms.

\section{Experimental}

2.1. Materials and Methods. UV/Vis double beam spectrophotometer, model-Shimadzu UV 1800 PC with $1 \mathrm{~cm}$ quartz cells was used. Standard bulk drug samples of LAF (99.45\% pure) and DOP (99.67\% pure) were provided as gift samples by Ajanta Pharmaceuticals Ltd, Mumbai, India and Cipla Ltd., Mumbai, India, respectively. The pharmaceutical dosage form used in this study was Lafaxid D tablets with a declared content of $10 \mathrm{mg}$ LAF and $10 \mathrm{mg}$ DOP USP per tablet (Zuventis healthcare Ltd., Mumbai).

2.2. Preparation of Solutions. LAF and DOP standard stock solution $(0.5 \mathrm{mg} / \mathrm{mL})$ was prepared by transferring accurately weighed $50 \mathrm{mg}$ portion of each drug in $100 \mathrm{~mL}$ volumetric flask, dissolved in $50 \mathrm{~mL}$ of methanol and volume was made up with distilled water to give concentration of $500 \mu \mathrm{g} / \mathrm{mL}$.

2.3. Methodology. Selection of analytical wavelengths was done by taking pure samples of LAF and DOP which were separately dissolved in methanol to give two solutions of 25 and $50 \mu \mathrm{g} / \mathrm{mL}$, respectively. They were scanned in the wavelength range of 200-400 nm. From the overlain spectra (Figure 3), wavelengths 279 and $284 \mathrm{~nm}$ were selected for 
TABLE 1: Determination of precision.

\begin{tabular}{lcccc}
\hline \multirow{2}{*}{ Sample number } & \multicolumn{3}{c}{ Assay of lafutidine and domperidone as \% of labeled amount } \\
& \multicolumn{2}{c}{ Analyst I (Intra-day precision) } & \multicolumn{2}{c}{ Analyst II (Inter-day precision) } \\
& LAF & DOP & LAF & 99.65 \\
\hline$(1)$ & 99.72 & 99.28 & 99.77 & 99.86 \\
$(2)$ & 99.93 & 99.52 & 99.97 & 99.29 \\
$(3)$ & 99.78 & 99.02 & 99.71 & 99.22 \\
$(4)$ & 99.90 & 99.35 & 99.88 & 99.49 \\
$(5)$ & 99.48 & 99.65 & 99.51 & 99.75 \\
$(6)$ & 99.20 & 99.31 & 99.25 & 99.54 \\
Mean & 99.67 & 99.35 & 99.68 & 0.24 \\
SD & 0.28 & 0.26 & 0.24 & \\
\hline
\end{tabular}

TABLE 2: Determination of accuracy by percentage recovery method.

\begin{tabular}{|c|c|c|c|c|c|c|c|}
\hline Ingredient & $\begin{array}{c}* \text { Tablet amount } \\
(\mu \mathrm{g} / \mathrm{mL})\end{array}$ & $\begin{array}{c}\text { Level of } \\
\text { addition (\%) }\end{array}$ & $\begin{array}{c}* \text { Amount added } \\
(\mu \mathrm{g} / \mathrm{mL})\end{array}$ & $\begin{array}{l}{ }^{*} \text { Total amount } \\
\text { taken from } \\
\text { tablet }(\mu \mathrm{g} / \mathrm{mL})\end{array}$ & $\begin{array}{l}\text { Amount } \\
\text { recovered } \\
(\mu \mathrm{g} / \mathrm{mL})\end{array}$ & \% Recovery & $\begin{array}{l}\text { Average \% } \\
\text { Recovery }\end{array}$ \\
\hline \multirow{3}{*}{ Lafutidine } & 10.00 & 80 & 8.4 & 18.4 & 18.34 & 99.67 & \multirow{3}{*}{$100.1 \pm 0.07611$} \\
\hline & 10.00 & 100 & 10.2 & 20.20 & 20.13 & 99.65 & \\
\hline & 10.00 & 120 & 12.23 & 22.23 & 22.45 & 100.98 & \\
\hline \multirow{3}{*}{ Domperidone } & 10.00 & 80 & 8.3 & 18.3 & 18.26 & 99.78 & \multirow{3}{*}{99.18} \\
\hline & 10.00 & 100 & 10.4 & 20.4 & 20 & 99.10 & \\
\hline & 10.00 & 120 & 12.6 & 22.6 & 22.1 & 98.67 & \\
\hline
\end{tabular}

*Amount equivalent to pure drug.

the formation of simultaneous equations. For constructing a calibration curves, two series of different concentrations in range of $10-150 \mu \mathrm{g} / \mathrm{mL}$ for LAF and $5-40 \mu \mathrm{g} / \mathrm{mL}$ for DOP were prepared from stock solutions. The calibration curves were plotted at 279 and $284 \mathrm{~nm}$. The absorptivities $(\mathrm{A} 1 \%, 1 \mathrm{~cm})$ of both the drugs at both the wavelengths were determined. These calculated values were the mean of five independent determinations. The absorbance and absorptivities values at the particular wavelengths were calculated and substituted in the Cramer's rule to obtain the concentrations:

$$
\begin{aligned}
& C x=\frac{A_{2} a y_{1}-A_{1} a y_{2}}{a x_{2} \cdot a y_{1}-a x_{1} \cdot a y_{2}}, \\
& C y=\frac{A_{1} a x_{2}-A_{2} a x_{1}}{a x_{2} \cdot a y_{1}-a x_{1} \cdot a y_{2}} .
\end{aligned}
$$

$C x$ and $C y$ are concentration of LAF hydrochloride and DOP, respectively, (in gram $/ 100 \mathrm{~mL}$ ) in sample solution. The validity of formed equations was checked by preparing five mixed standards, measuring their absorbances at respective wavelengths and comparing these with the absorbances calculated using above formed equations.

2.4. Estimation from Tablets. The pharmaceutical dosage form used in this study was Lafaxid D tablets with a declared content of $10 \mathrm{mg}$ LAF and $10 \mathrm{mg}$ DOP USP per tablet (Zuventis healthcare Ltd, Mumbai).

Twenty tablets of brand Lafaxid D tablets were weighed and finely powdered. Accurately weighed tablet powder

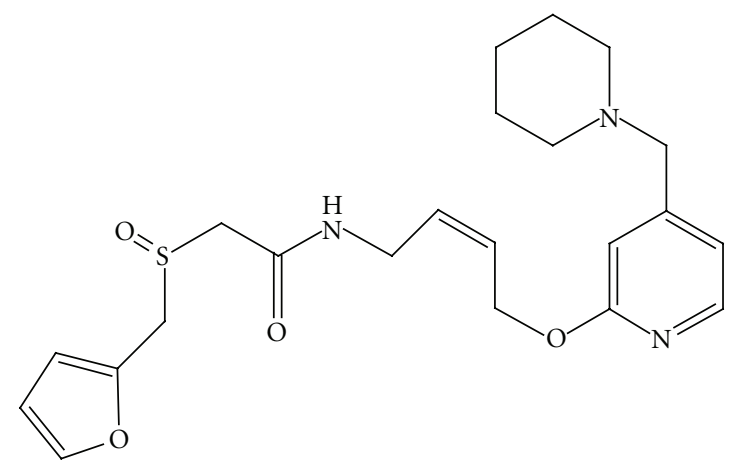

FIgURE 1: Structure of lafutidine.<smiles>O=c1[nH]c2ccccc2n1CCCN1CCC(n2c(=O)[nH]c3cc(Cl)ccc32)CC1</smiles>

Figure 2: Structure of domperidone.

equivalent to $10 \mathrm{mg}$ was taken in $100 \mathrm{~mL}$ volumetric flask. $20 \mathrm{~mL}$ of methanol was added and sonicated for $5 \mathrm{~min}$. The volume was made to mark with distilled water. Aliquot 
TABLE 3: Summary of validation parameters.

\begin{tabular}{|c|c|c|c|}
\hline Sr. no. & Parameter & LAF & DOP \\
\hline (1) & Absorption maxima $(\mathrm{nm})$ & 279 & 284 \\
\hline (2) & Linearity range $(\mu \mathrm{g} / \mathrm{mL})$ & $10-100$ & $5-40$ \\
\hline (3) & Standard regression equation & $y=0.818 x+0.208$ & $y=1.552 x-0.036$ \\
\hline (4) & Correlation coefficient $\left(r^{2}\right)$ & 0.999 & 0.997 \\
\hline (5) & Molar absorptivity & 2608 & 11480 \\
\hline \multirow{2}{*}{ (6) } & \multirow{2}{*}{$\mathrm{A}(1 \%, 1 \mathrm{~cm})$} & $\lambda_{1}=60.52$ & $\lambda_{1}=279$ \\
\hline & & $\lambda_{2}=56.08$ & $\lambda_{2}=304$ \\
\hline (7) & Accuracy $(\%$ recovery $\pm S D)$ & & \\
\hline (8) & Precision (\% CV) & & \\
\hline (9) & Limit of quantitation $(\mu \mathrm{g} / \mathrm{mL})$ & 2.08 & 0.479 \\
\hline (10) & Limit of detection $(\mu \mathrm{g} / \mathrm{mL})$ & 6.11 & 1.45 \\
\hline
\end{tabular}

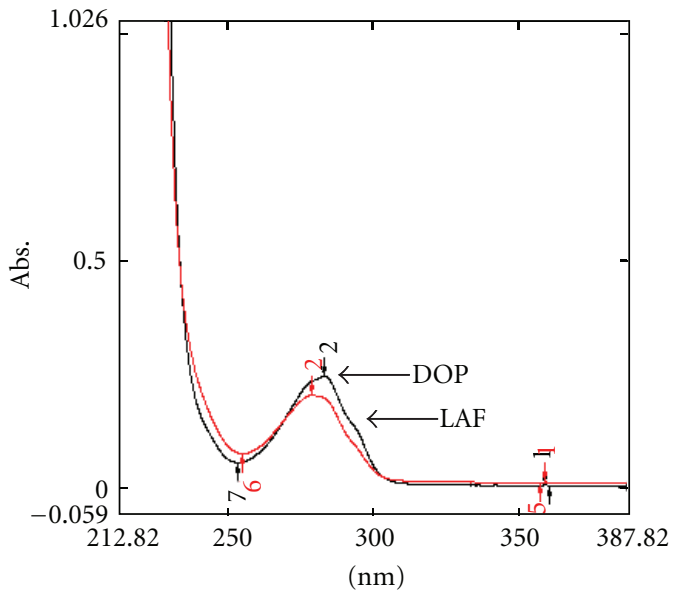

Figure 3: Overlain spectra of LAF and DOP (400-200 nm).

portion of this solution was further diluted to achieve final concentration of $25 \mu \mathrm{g} / \mathrm{mL}$ for LAF and DOP. The absorbances were noted at respective wavelengths. The concentration of each drug in tablet formulation was determined using above methods.

\section{Result and Discussion}

The overlain spectra of LAF and DOP in the concentration ratio of $1: 1$ showed that the peaks are resolved, thus satisfactory criteria for obtaining maximum precision based on absorbance ratios. The criteria being the ratios $\left(A_{2} A_{1} / a X_{2} a X_{1}\right)$ for drug Y and $\left(a Y_{2} a Y_{1} / A_{1} A_{2}\right)$ for drug X should lie outside the range of $0.1-2.0$ where $A_{1}$ and $A_{2}$ represent absorbance of tablet solution at $\lambda_{1}$ and $\lambda_{2}, a X_{1}$ and $a X_{2}$ represent absorptivities of $X$ at $\lambda_{1}$ and $\lambda_{2}$, and $a Y_{1}$ and $a Y_{2}$ denote absorptivities of $Y$ at $\lambda_{1}$ and $\lambda_{2}$, respectively. In the present contest, the above criteria was found to be satisfing for LAF (X) and DOP (Y) where $\lambda_{1}$ is $279 \mathrm{~nm}$ and $\lambda_{2}$ is $284 \mathrm{~nm}$. In overlain spectra, LAF shows two distinct peaks, one at around 230 and the other at $279 \mathrm{~nm}$. The peak at $279 \mathrm{~nm}$ was found to be prominent hence for simultaneous equations method; the peak was used for determination of LAF. Since only one prominent peak exists for DOP at $284 \mathrm{~nm}$, the same was used for its determination. Absorbance was determined at the both wavelengths.

Calibration curves were plotted and regression analysis was carried out. The linearity range of LAF was found to be $10-100 \mu \mathrm{g} / \mathrm{mL}$ and for DOP $5-40 \mu \mathrm{g} / \mathrm{mL}$. The absorpitivity was then calculated and substituted in (1) along with absorbance values to obtain concentration of drugs.

3.1. Validation. LOD and LOQ were calculated, in accordance with ICH guidelines, as $3.3 r / S$ and $10 r / S$, respectively, where $r$ is the standard deviation of the response $(y$ intercept) and $S$ is the slope of the calibration plot. To study intraday variation, six mixed standard solutions containing LAF $(50 \mu \mathrm{g} / \mathrm{mL})$ and DOP $(50 \mu \mathrm{g} / \mathrm{mL})$ were prepared and absorbance was taken. All the solutions were analyzed on the same day to record any intraday variation in the results. To study interday variation, analysis of three mixed standard solutions of the same concentration was performed on different days (Table 1).

3.2. Recovery Studies. To check the accuracy of the method, recovery was measured by addition of standard drug solution at three different levels $(80,100$, and $120 \%)$ to preanalyzed sample solution (Table 2).

By observing the validation parameters (Table 3 ), the method was found to be specific, accurate, precise, repeatable, and reproducible. Hence, this method can be employed for routine analysis of tablet for assay as well as dissolution testing.

\section{Conclusion}

Simple, new, simultaneous UV spectroscopic method was developed and validated. The proposed method is accurate, precise, reproducible, and economical and can be successfully used for routine analysis of simultaneous estimation of lafutidine and domperidone. 


\section{Acknowledgment}

The authors would like to thank Shri Rambhau Moze, Honorable President of Genba Sopanrao Moze Trust for his kind support.

\section{References}

[1] W. D. Chen, Y. Liang, H. Li et al., "Simple, sensitive and rapid LC-ESI-MS method for the quantitation of lafutidine in human plasma-application to pharmacokinetic studies," Journal of Pharmaceutical and Biomedical Analysis, vol. 41, no. 1, pp. 256260, 2006.

[2] Y. Akiba and J. D. Kaunitz, "Lafutidine, a protective $\mathrm{H}_{2}$ receptor antagonist, enhances mucosal defense in rat esophagus," Digestive Diseases and Sciences, vol. 55, no. 11, pp. 3063-3069, 2010.

[3] I. L. Swann, E. N. Thompson, and K. Qureshi, "Domperidone or metoclopramide in preventing chemotherapeutically induced nausea and vomiting," BMJ, vol. 2, no. 6199, article $118,1979$.

[4] A. Karthik, G. Subramanian, A. Ranjith Kumar, and N. Udupa, "Simultaneous estimation of paracetamol and domperidone in tablets by reverse phase HPLC method," Indian Journal of Pharmaceutical Sciences, vol. 69, no. 1, pp. 142-144, 2007.

[5] M. Kobylińska and K. Kobylińska, "High-performance liquid chromatographic analysis for the determination of domperidone in human plasma," Journal of Chromatography B, vol. 744, no. 1, pp. 207-212, 2000.

[6] M. Cignitti, M. C. Ramusino, and L. Rufini, "UV spectroscopic study and conformational analysis of domperidone," Journal of Molecular Structure, vol. 350, no. 1, pp. 43-47, 1995.

[7] B. H. Patel, B. N. Suhagia, M. M. Patel, and J. R. Patel, "HPTLC determination of rabeprazole and domperidone in capsules and its validation," Journal of Chromatographic Science, vol. 46, no. 4, pp. 304-307, 2008.

[8] Y. Xing and H. Fa, "Determination of lafutidine and its tablets by HPLC," Journal of Zhejiang University. Science. B, vol. 6, no. 1, pp. 74-78, 2005.

[9] C. X. Pan, X. Z. Xu, H. M. He, X. J. Cai, and X. J. Zhang, "Separation and identification of cis and trans isomers of 2butene-1,4-diol and lafutidine by HPLC and LC-MS," Pharmaceutical Journal, vol. 6, 2003. 


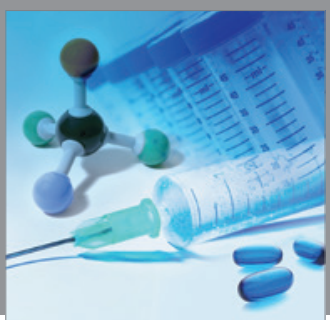

International Journal of

Medicinal Chemistry

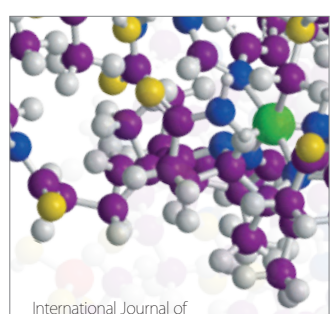

Carbohydrate Chemistry

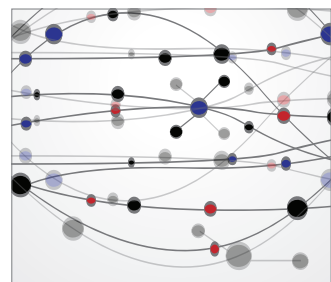

The Scientific World Journal
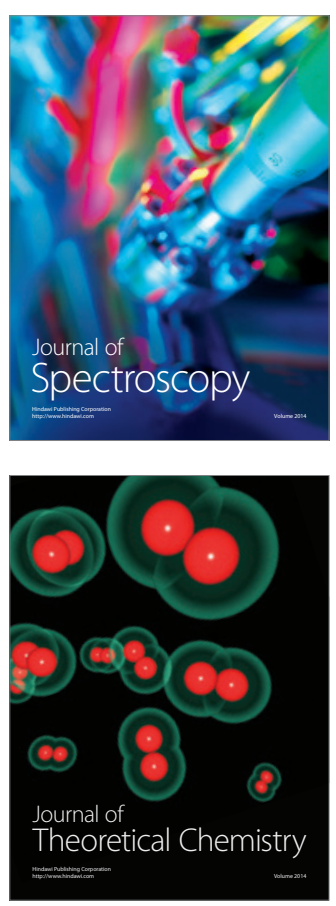
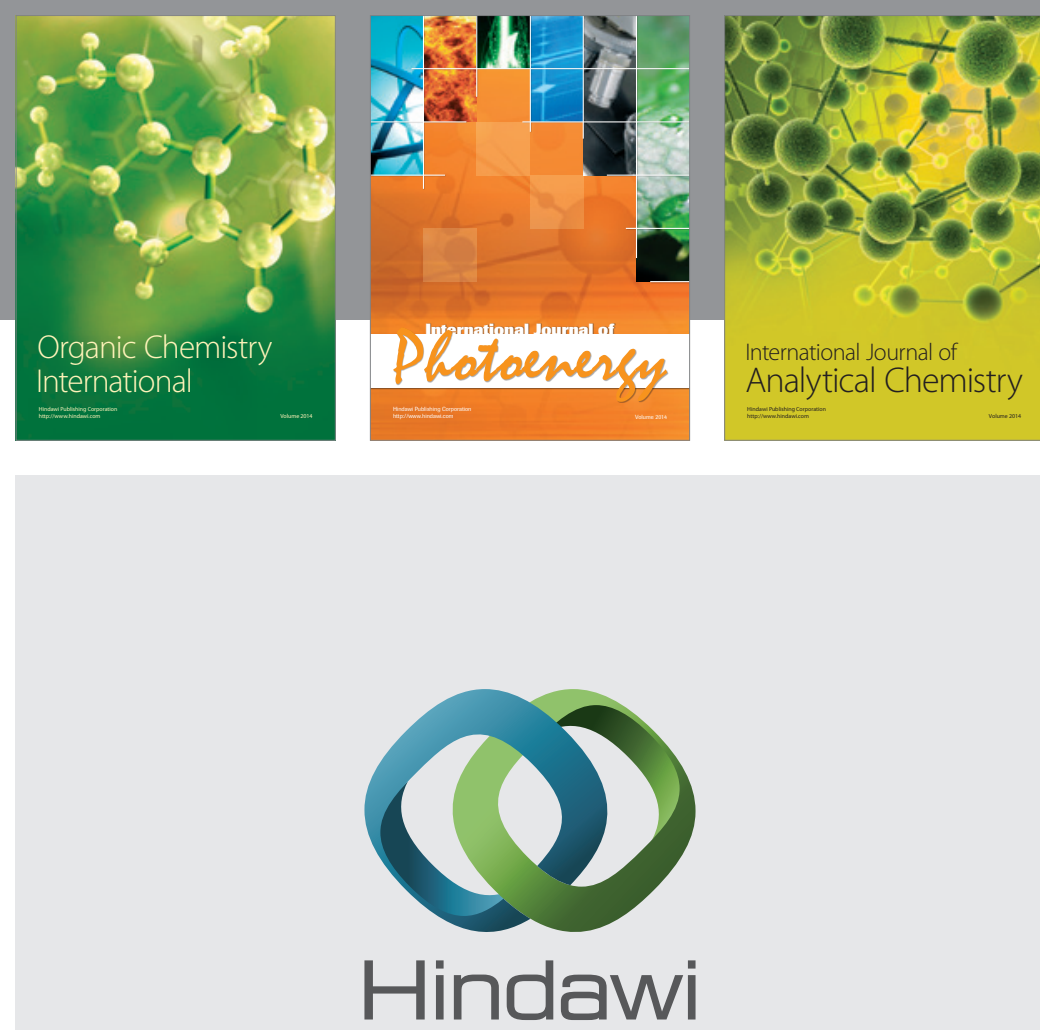

Submit your manuscripts at

http://www.hindawi.com
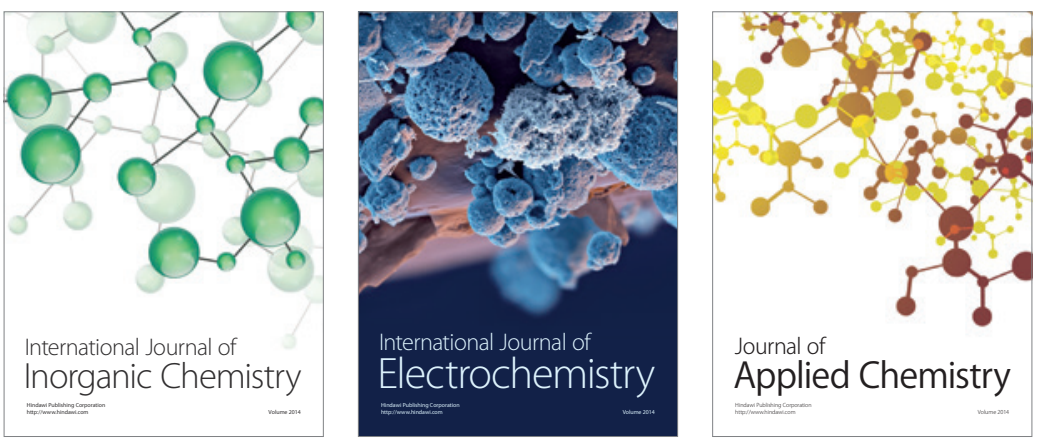

Journal of

Applied Chemistry
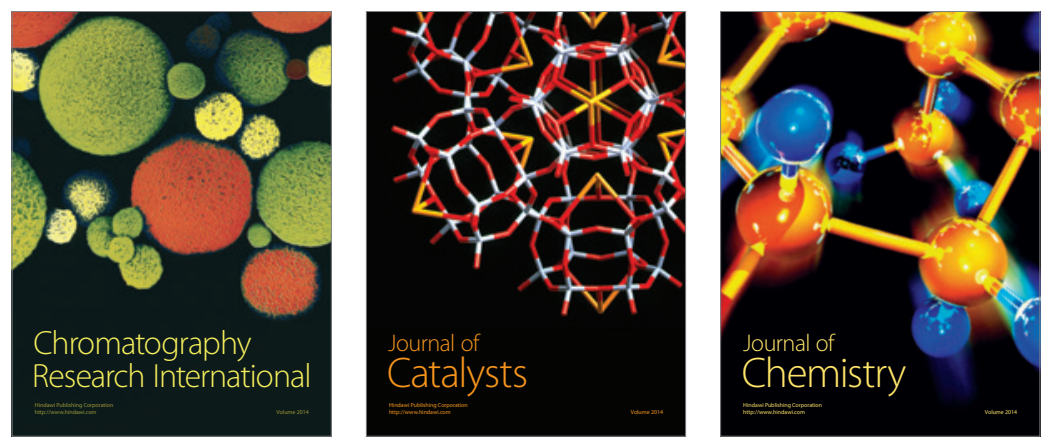
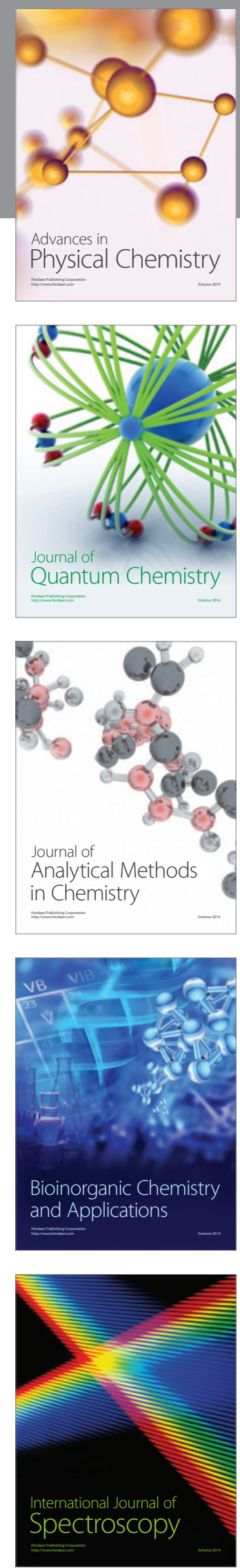